\title{
One-pot controlled reduction of conjugated amides by sequential double hydrosilylation catalyzed by an iridium(III) metallacycle
}

\author{
Yann Corre, ${ }^{[a]}$ Vincent Rysak, ${ }^{[a]}$ Márton Nagyházi, ${ }^{[a]}$ Dorottya Kalocsai, ${ }^{[a]}$ Xavier Trivelli, ${ }^{[b]}$ \\ Jean-Pierre Djukic, ${ }^{[c]}$ Francine Agbossou-Niedercorn, ${ }^{*[a]}$ and Christophe Michon*[a,d]
}

[a] Y. Corre, V. Rysak, M. Nagyházi, D. Kalocsai, Dr. F. Agbossou-Niedercorn, Dr. C. Michon

UCCS UMR 8181

Univ. Lille, CNRS, Centrale Lille, Univ. Artois, UMR 8181 - UCCS - Unité de Catalyse et Chimie du Solide

F-59000 Lille, France.

[b] Dr. X. Trivelli

IMEC - Institut Michel-Eugène Chevreul FR 2638

Univ. Lille, CNRS, INRA, Centrale Lille, Univ. Artois, FR 2638 - IMEC -Institut Michel-Eugène Chevreul

F-59000 Lille, France.

[c] Dr. J.-P. Djukic

Institut de Chimie de Strasbourg, CNRS UMR 7177

Université de Strasbourg

4 rue Blaise Pascal F-67000 Strasbourg, France.

[d] Dr. C. Michon (new address)

Ecole Européenne de Chimie, Polymères et Matériaux - LIMA UMR 7042

Université de Strasbourg, Université de Haute-Alsace, Ecole Européenne de Chimie, Polymères et Matériaux, CNRS,

LIMA, UMR 7042

25 rue Becquerel, F-67087 Strasbourg, France.

Email: cmichon@unistra.fr

Supporting information for this article is available free of charge on the internet.

\begin{abstract}
A single and accessible cationic iridium "II metallacycle catalyzes effectively the one-pot sequential double hydrosilylation of challenging $\alpha, \beta$-unsaturated secondary and tertiary amides to afford in a controlled and straightforward way the corresponding reduced products, that is to say the related secondary and tertiary amides and amines. The catalytic hydrosilylations of the conjugated amides described herein proceeded in good yields and high chemoselectivities. The critical silyl enolate, in other words silyl ketene aminal intermediate, has been observed and characterized by using control experiments, mass spectrometry and state of the art Nuclear Magnetic Resonance analyses. The present achievements indicate a promising potential of catalysts based on metallacycles for future significant developments in one-pot multicatalytic synthesis and therefore the production of highly functionalized and complex organic molecules.
\end{abstract}

\section{Introduction}

The quests for chemically effective syntheses of commodity and complex chemicals with lower waste production, minimal physical separation operations and catalyst's recyclability are now the major challenges in the domain of homogenous catalysis for economic and environmental benefits. These challenges are embodied nowadays into new strategies of research wherein efficiency, selectivity as well as modularity and adaptivity of catalytic systems are the main goals. ${ }^{[1]}$ Sequential multimetallic catalysis, ${ }^{[2]}$ cooperative and non-cooperative dual catalysis ${ }^{[3]}$ as well as tandem catalysis ${ }^{[4]}$ are presently some of the developed approaches towards one-pot multicatalytic synthesis. ${ }^{[1,5]}$ Among those, sequential double hydrofunctionalization of alkynes has recently received a rising interest. Consecutive reactions like hydroamination-hydrogenation, hydroboration-hydrogenation, hydroboration-hydrosilylation have allowed powerful and selective pot-economical conversions of bulk materials to highly functionalized molecules. ${ }^{[6]}$

The selective reduction of carbon-carbon double bonds in $\alpha, \beta$-unsaturated carbonyl compounds still remains challenging in hydrogenation ${ }^{[7]}$ and hydrosilylation ${ }^{[8]}$ due to several competing reactions: 1,2 -addition, 1,4 -additions, $\alpha$ - or $\beta$-additions to the alkene, de-oxygenation or even polymerizations. Interestingly, among the possible 1,4-addition products, metal- (or silyl-) enol ethers or ketene acetals, are versatile nucleophiles in Mukaiyama aldol, Michael reactions, allylic alkylations, asymmetric protonations and haloketone or ketol formations. ${ }^{[9]}$
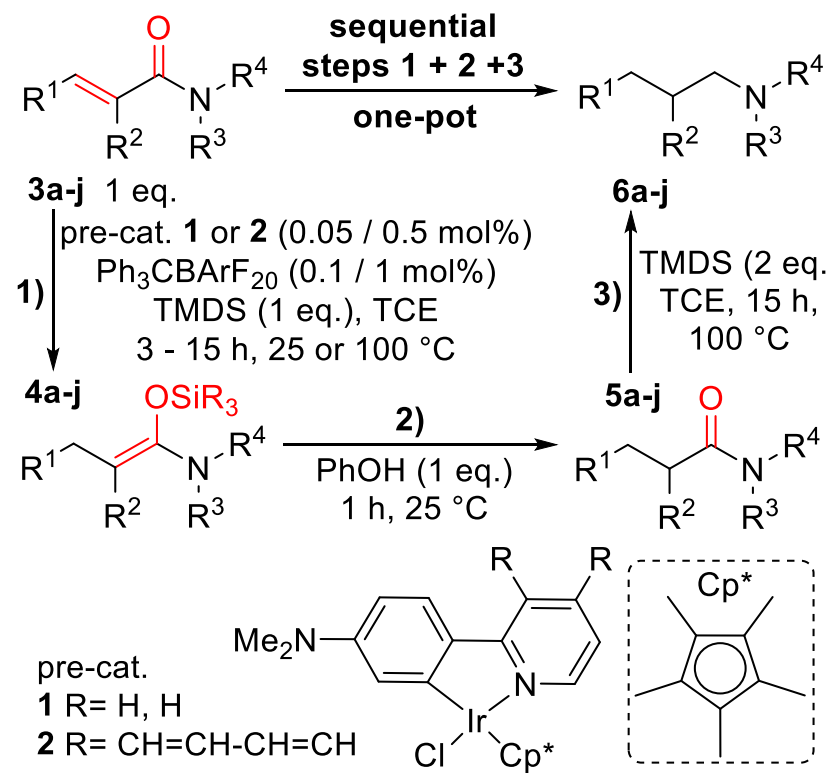

Scheme 1. Sequential hydrosilylation of enamides $3 a-j$ into silyl ketene aminal 4a-j, amides 5a-j and amines 6a-j using iridacycle catalyst $\mathbf{1}$ or $\mathbf{2}$. 
Although there have been efforts made to achieve chemoselective $\mathrm{C}-\mathrm{C}$ hydrosilylation of $\alpha, \beta$-unsaturated ketones and esters, ${ }^{[8]}$ there are, to the best of our knowledge, very few examples of chemoselective hydrosilylation of $\alpha, \beta$-unsaturated amides ${ }^{[10]}$ and no sequential hydrofunctionalization of enamides. Moreover, the catalytic carbon-carbon and carbon-heteroatom bond formation at the $\alpha$-position of amides remains challenging..$^{[11]}$ Because of the hydrogens of amides or esters being much less acidic than those of aldehydes or ketones, amides are relunctant to form enolates, i.e. silyl ketene aminals. Up to now, only few catalytic methods have been able to form such a critical intermediate and enable alkylation, ${ }^{[11 \mathrm{~b}]}$ 1,4-addition, ${ }^{[11 \mathrm{c}]}$ Mannichtype reaction ${ }^{[11 \mathrm{~d}]}$ and $\alpha$-amination. ${ }^{[11 \mathrm{e}]}$ Following our ongoing interest in metal catalyzed hydrosilylation reactions of C-C and Cheteroatom unsaturated compounds, ${ }^{[12]}$ we report herein the application of an accessible iridium ${ }^{\text {III }}$ metallacycle like $\mathbf{1}$ or $\mathbf{2}$ to catalyze the first one-pot sequential double hydrosilylation of secondary and tertiary $\alpha, \beta$-unsaturated amides $3 a-j$ to afford in a controlled and chemoselective way the related silyl ketene aminal 4a-j, amides 5a-j and amines 6a-j (Scheme 1).

\section{Results and Discussion}

Our investigations on the double reduction of $\alpha, \beta$-unsaturated amides started by studying the first step of the targeted sequential reaction, i.e. the hydrosilylation of the conjugated CC double bond The use of iridium ${ }^{\text {III }}$ catalyst precursors, additives and reaction conditions was directly inspired by our previous study on hydrosilylation reactions of secondary and tertiary amides using chlorinated iridium ${ }^{\text {III }}$ metallacycles $\mathbf{1}$ and $\mathbf{2}$ as pre-catalysts, trityltetra(pentafluorophenyl)borate $\left(\mathrm{Ph}_{3} \mathrm{CBArF}_{20}\right)$ as the dechlorination agent, 1 equivalent of inexpensive 1,1,3,3tetramethyldisiloxane (TMDS) as reducing agent and dichloromethane as a solvent (Scheme 1, Table 1). ${ }^{[12 h]}$
The chlorinated iridium "II metallacycles 1 and $\mathbf{2}$ were respectively based on 2-phenylpyridine and 1-phenylisoquinoline chelating ligands, both functionalized by a $\mathrm{NMe}_{2}$ - electron donating group. As already demonstrated in our previous studies, such a feature is critical in order to get a higher hydricity for the transient metalhydride species (i.e. a feature of strong hydride donor) and therefore a faster reduction of the organic unsaturation for a highest catalytic activity. ${ }^{[12 h]}$ At first, the hydrosilylation of tertiary conjugated amides 3 a was performed using 0.05 mol\% of catalyst 1 or 2 in combination with $0.1 \mathrm{~mol} \%$ of $\mathrm{Ph}_{3} \mathrm{CBArF}_{20}$ and 1 equivalent of TMDS (entries 1,2). Whereas reduced amide 5a was rapidly obtained in a high yield using pre-catalyst 1 at $25^{\circ} \mathrm{C}$, no reaction was observed with pre-catalyst 2 . Though the catalytic reaction could proceed at $100{ }^{\circ} \mathrm{C}$ in $1,1^{\prime}, 2,2^{\prime}$-tetrachloroethane (TCE), the lower reactivity of iridacycle 2 at $25^{\circ} \mathrm{C}$ was rather surprising in reference to its high performances in the hydrosilylation of challenging bulky secondary and tertiary amides. ${ }^{[12 h]}$ The scope of the hydrosilylation reaction was then studied with aromatic and aliphatic tertiary conjugated amides 3b-f (Table 1). Under the optimized conditions described above, the corresponding amides $\mathbf{5 b - f}$ were obtained generally in high to quantitative yields (entries 3-7). By comparison to conjugated amides $\mathbf{3 a}$ and $\mathbf{3 d}$, substrate $\mathbf{3 e}$ issued from trans-2-methyl-2butenoic acid and dibenzylamine led to a moderate yield of $\mathbf{5 e}$ (entry 6). This indicated possible limitations of the 1,4-addition reaction to trisubstituted substrates. Afterwards, the scope of the hydrosilylation reaction was studied with aromatic and aliphatic secondary conjugated amides $\mathbf{3 g}-\mathbf{j}$ (Table 1 , entries $8-11$ ). Due to the lower reactivity of secondary amides, ${ }^{[12 h, 13]}$ higher loadings of catalyst $1(0.5 \mathrm{~mol} \%)$ and $\mathrm{Ph}_{3} \mathrm{CBArF}_{20}(1 \mathrm{~mol} \%)$ were required in order to allow the reaction to proceed smoothly and get high yields of amides $\mathbf{5 g}$-j. With the exception of $\mathbf{3 g}$ which required a 15 hours reaction time, other conjugated amides $3 \mathrm{~h}-\mathrm{j}$ were effectively reduced in few hours at $25^{\circ} \mathrm{C}$.

Table 1. Hydrosilylation of enamides $3 a-j$ into amides $5 a-j$ using catalyst 1 or 2 .

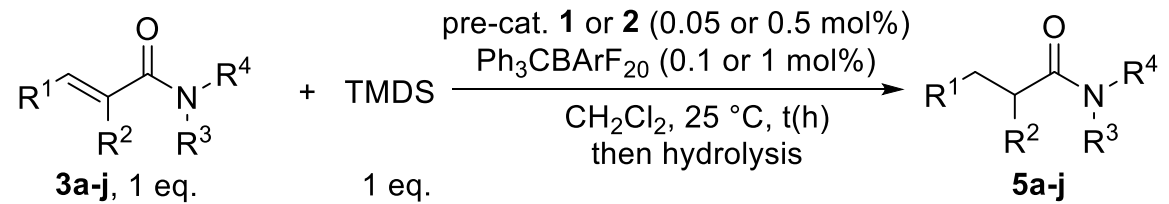

\begin{tabular}{|c|c|c|c|c|c|c|c|c|}
\hline Entry & $\begin{array}{c}\text { Enamide } \\
\mathbf{3}\end{array}$ & $\mathrm{R}^{1}$ & $\mathrm{R}^{2}$ & $\mathrm{R}^{3}$ & $\mathrm{R}^{4}$ & $\begin{array}{l}\text { pre-cat } \\
(\mathrm{mol} \%)\end{array}$ & $t(h)$ & $\begin{array}{l}\text { Yield (\%) }{ }^{[a]} \\
\text { (isolated } \\
\text { yield \%) }{ }^{[b]}\end{array}$ \\
\hline $1^{[c]}$ & $3 a$ & $\mathrm{Ph}$ & $\mathrm{H}$ & $\mathrm{Bn}$ & $\mathrm{Bn}$ & $1(0.05)$ & 0.5 & $5 a 100(90)$ \\
\hline 2 & $3 a$ & $\mathrm{Ph}$ & $\mathrm{H}$ & $\mathrm{Bn}$ & $\mathrm{Bn}$ & $2(0.05)$ & 14 & $5 \mathbf{a} 0(-)^{[\mathrm{c}]}$ \\
\hline 3 & $3 b$ & $\mathrm{Ph}$ & $\mathrm{H}$ & \multicolumn{2}{|c|}{$-\left(\mathrm{CH}_{2}\right)_{2}-\mathrm{O}-\left(\mathrm{CH}_{2}\right)_{2}-$} & $1(0.05)$ & 14 & 5b $100(61)$ \\
\hline 4 & $3 c$ & $\mathrm{Ph}$ & $\mathrm{H}$ & $\mathrm{Me}$ & $\mathrm{Me}$ & $1(0.05)$ & 14 & 5c $100(77)$ \\
\hline 5 & $3 d$ & $\mathrm{H}$ & $\mathrm{Me}$ & $\mathrm{Bn}$ & $\mathrm{Bn}$ & $1(0.05)$ & 0.5 & 5d 98 (98) \\
\hline 6 & $3 e$ & $\mathrm{Me}$ & $\mathrm{Me}$ & $\mathrm{Bn}$ & $\mathrm{Bn}$ & $1(0.05)$ & 24 & 5e 37 (31) \\
\hline 7 & $3 f$ & $\mathrm{Ph}$ & $\mathrm{H}$ & $\mathrm{Me}$ & $\mathrm{Ph}$ & $1(0.05)$ & 2 & $5 \mathbf{f} 98(76)$ \\
\hline 8 & $3 g$ & $\mathrm{Ph}$ & $\mathrm{H}$ & $\mathrm{H}$ & $n$-Bu & $1(0.5)$ & 15 & $5 \mathrm{~g} 88^{[\mathrm{d}]}(84)$ \\
\hline 9 & $3 h$ & $\mathrm{Ph}$ & $\mathrm{H}$ & $\mathrm{H}$ & $\mathrm{Bn}$ & $1(0.5)$ & 6 & 5h 100 (89) \\
\hline 10 & $3 \mathbf{i}$ & $\mathrm{Ph}$ & $\mathrm{H}$ & $\mathrm{H}$ & $\mathrm{Ph}$ & $1(0.5)$ & 0.5 & $5 i 100(90)$ \\
\hline 11 & $3 \mathbf{j}$ & $\mathrm{Ph}$ & $\mathrm{H}$ & $\mathrm{H}$ & $-\mathrm{CH}_{2}$-1-thiophene & $1(0.05)$ & 4 & 5j $100(100)$ \\
\hline
\end{tabular}

$[\mathrm{b}]$ isolated yield $(\%)$ after flash chromatography or recrystallisation. [c] $90 \%$ yield of 5 a at $100^{\circ} \mathrm{C}$ in $1,1^{\prime}, 2,2^{\prime}$-tetrachloroethane (TCE). [d] along with $12 \%$ of the related secondary amine. 


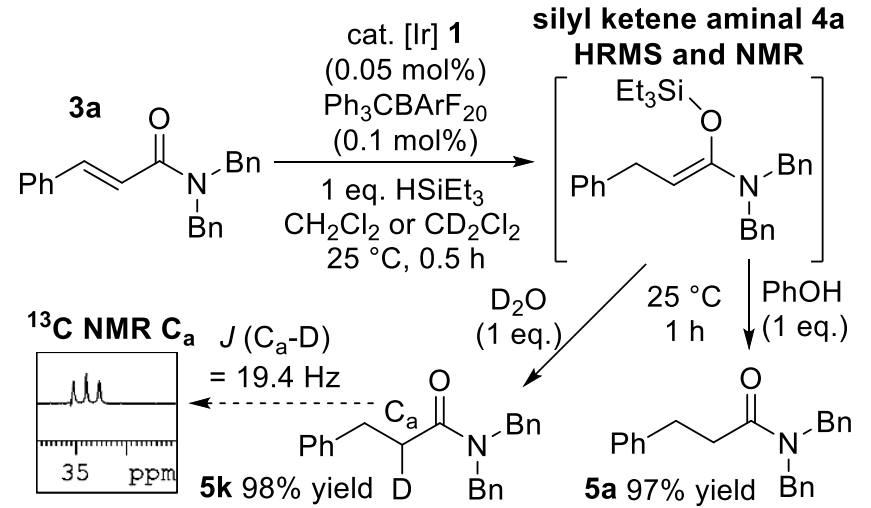

Scheme 2. Sequential hydrosilylation of enamides $\mathbf{3 a}$ into silyl ketene aminal $4 \mathbf{a}$ and amide $5 \mathbf{a}$.

We next focused on the characterization of the silyl ketene aminal 4 a (Schemes 1 and 2). At first, the hydrosilylation of enamide $3 \mathbf{a}$ was studied using pre-catalyst $1, \mathrm{Ph}_{3} \mathrm{CBArF}_{20}$ and 1 equivalent of $\mathrm{Et}_{3} \mathrm{SiH}$ in $\mathrm{CH}_{2} \mathrm{Cl}_{2}$ at $25^{\circ} \mathrm{C}$ during 30 minutes (Scheme 2). In the prospect of performing a second hydrosilylation reaction, we had to exclude water due to the high sensitivity of the catalytic system. Therefore, we found the silyl enolate / silyl ketene aminal 4a resulting from a hydrosilylation through a 1,4-addition was smoothly protonated by an equivalent of phenol to afford amide 5a. Three different alcohols, i.e. Gaiacol, isopropanol and phenol, were tested for the protodesilylation of 4a (Table S1). Phenol, the most acidic and the less coordinating reagent, led to $\mathbf{5 a}$ in $97 \%$ yield after 30 minutes of reaction. The silyl ketene aminal $4 a$ was first evidenced by a reaction with $\mathrm{D}_{2} \mathrm{O}$ and formation of deuterated amide $\mathbf{5 k}$ (Scheme 2). After purification by flash chromatography, product $\mathbf{5 k}$ was characterized by ${ }^{1} \mathrm{H}$ and ${ }^{13} \mathrm{C}$ NMR (Figure $\mathrm{S} 1$ and Figure S2) as well as by HRMS ESI (+) (Figure S3). It was worth to compare the coupling of benzylic protons of deuterated amide $\mathbf{5 k}$ with those of 5a (see Figure 51 ). While a triplet was observed for $\mathbf{5 a}$, a doublet was observed for $\mathbf{5 k}$ due to the neighboring deuterium. Moreover, the ${ }^{13} \mathrm{C}$ NMR spectrum of $\mathbf{5 k}$ confirmed the presence of a deuterium because a triplet resulting from the coupling of deuterium (spin 1) and carbon nuclei $C_{a}$ (spin 1/2) $\left(J C_{a}-D=19.4\right.$ $\mathrm{Hz}$ ) was observed at $34.8 \mathrm{ppm}$ (Scheme 2, Figure S2).

In another experiment, the hydrosilylation of enamide $\mathbf{3 a}$ was performed under the same reaction conditions, i.e. in $\mathrm{CD}_{2} \mathrm{Cl}_{2}$ using pre-catalyst $1, \mathrm{Ph}_{3} \mathrm{CBArF}_{20}$ additive and 1 equivalent of $\mathrm{Et}_{3} \mathrm{SiH}$ at $25^{\circ} \mathrm{C}$ during 30 minutes (Schemes 2 and S2). The mass spectrometry ESI-(+) analysis of a reaction mixture aliquot diluted in dry acetonitrile showed evidence of the silyl ketene aminal $4 a$ and the related sodium ketene aminal $\mathbf{4 b}$ along with amide $5 \mathrm{a}$ and several side products issued from a bimolecular 1,4-addition ${ }^{[14]}$ and a Diels-Alder [4+2]-cycloaddition (Figure S4, Scheme S3). Furthermore, the crude solution of silyl enolate / silyl ketene aminal 4a was transfered in a dry NMR Young tube under argon in order to be studied. ${ }^{1} \mathrm{H}$ and ${ }^{1} \mathrm{H}-{ }^{1} \mathrm{H}$ COSY NMR analyses confirmed the molecular structure of 4 a (Figures S5 and S7). We could identify the scalar couplings between some key spin systems like: an ethyl, a benzyl and a $\mathrm{Ph}-\mathrm{CH}_{2}-\mathrm{CH}$ system (Scheme S4). The conventional correlations were observed through the ${ }^{3} \mathrm{~J}(\mathrm{H}, \mathrm{H})$ coupling constants (ethyl, $\mathrm{CH}_{2}-\mathrm{H}$ ) as well as through the weak ${ }^{4} \mathrm{~J}(\mathrm{H}, \mathrm{H})$ of the benzylic systems. This defined the chemical shifts of the ortho aromatic protons and supported the molecular structure of silyl ketene aminal $\mathbf{4 a}$. The latter was further confirmed by ${ }^{13} \mathrm{C}$ and ${ }^{1} \mathrm{H}-{ }^{13} \mathrm{C}$ HSQC NMR experiments (Figures S6 and S8). Among the observed ${ }^{13} \mathrm{C}$ and ${ }^{1} \mathrm{H}$ NMR chemical shifts, the most significants were the non-aromatic olefin carbon at $90.5 \mathrm{ppm}$ and the related proton at $3.75 \mathrm{ppm}$, which were typical of an enolate system like $4 a$ (Scheme S4). A further NMR analysis by NOESY ${ }^{1} \mathrm{H}-{ }^{1} \mathrm{H}$ confirmed the molecular structure of silyl ketene aminal 4a. The ethyl, benzyl and $\mathrm{Ph}-\mathrm{CH}_{2}-\mathrm{CH}$ spin systems which were observed by ${ }^{1} \mathrm{H}-{ }^{1} \mathrm{H}$ COSY were part of the same molecule as confirmed by unambiguous NOEs (Scheme S4). The two benzyl groups on the nitrogen and the three ethyl of the silicon were all in fast exchange and led to single couplings. The three phenyl groups were on free rotation. The NOE between the olefin proton and those of the benzyl groups of the nitrogen ($\mathrm{CH}_{2}$ ) was hardly observed due to the close chemical shifts (3.75 and $3.91 \mathrm{ppm})$. There was no NOE observed between the olefin proton $(3.75 \mathrm{ppm})$ and the ortho- aromatic protons $(7.15 \mathrm{ppm})$ of the $\mathrm{Ph}-\mathrm{CH}_{2}-\mathrm{CH}$ spin system, these protons being not close to each other. Finally, the last NMR experiment by ${ }^{29} \mathrm{Si} \mathrm{HSQC}$ highlighted the main correlation observed through the ${ }^{2} J(\mathrm{Si}-\mathrm{H})$ and ${ }^{3} \mathrm{~J}(\mathrm{Si}-\mathrm{H})$ with a ${ }^{29} \mathrm{Si}$ chemical shift of $+21.0 \mathrm{ppm}$ and could be in agreement with a silicon atom bound to three carbons and one oxygen, the ${ }^{29} \mathrm{Si}$ chemical shift for $\mathrm{HSiEt}_{3}$ being of $+0.2 \mathrm{ppm}$. ${ }^{[15]}$

Once the protodesilylation of silyl ketene aminal $\mathbf{4}$ had been set in anhydrous conditions, we studied the scope of the sequential double hydrosilylation reaction of aromatic and aliphatic conjugated amides $\mathbf{3 a - j}$ into amines $\mathbf{6 a - j}$ (Table 2). Similar to the hydrosilylation of the conjugated $\mathrm{CC}$ double bond, the double hydrosilylation of the conjugated $\mathrm{CC}$ and $\mathrm{CO}$ double bonds was performed using: $0.05 \mathrm{~mol} \%$ of catalyst 1 or 2 and 0.1 mol\% of $\mathrm{Ph}_{3} \mathrm{CBArF}_{20}$ for tertiary amides 3a-f and, using $0.5 \mathrm{~mol} \%$ of catalyst 1 or 2 and $1 \mathrm{~mol} \%$ of $\mathrm{Ph}_{3} \mathrm{CBArF}_{20}$ for secondary amides 3g-j. ${ }^{[12 h, 13]}$ All reactions were run according to a one-pot and 3 steps procedure. The first step accomplished the hydrosilylation of the conjugated CC double bond using one equivalent of TMDS. In order to accelerate these catalytic reactions, they were run at $100{ }^{\circ} \mathrm{C}$ in $1,1^{\prime}, 2,2^{\prime}$-tetrachloroethane (TCE) for 3 hours. After cooling, the second step, i.e. the protodesilylation of silyl ketene aminals 4a-j, proceeded by reaction with one equivalent of recrystallized phenol dissolved in dry TCE at $25^{\circ} \mathrm{C}$ for 1 hour. Afterwards, the third step, i.e. the hydrosilylation of the amide $\mathrm{CO}$ bonds, was performed based on our previous study on hydrosilylation of secondary and tertiary amides. ${ }^{[12 h]}$ Two additional equivalents of TMDS were added to the reaction mixture which was subsequently heated to $100{ }^{\circ} \mathrm{C}$ for 15 hours. At the exception of reagent $3 \mathbf{a}$ which was better reduced using catalyst $\mathbf{1}$, the sequential double hydrosilylations of tertiary conjugated amides $\mathbf{3 b - f}$ were conducted along with catalyst 2 (entries 1-12). The desired amines 6a-f were isolated in fair to high yields. We noticed the reaction of substrates $3 \mathbf{b}, \mathbf{d}, \mathbf{e}$ bearing donor substituents led to the expected amines $\mathbf{6 b}, \mathbf{d}, \mathbf{e}$ as major products along with some amounts of amides $\mathbf{5 b}$,d,e (entries 3 4,7-10). Regarding the sequential double hydrosilylation of secondary conjugated amides $\mathbf{3 g}-\mathbf{j}$, the corresponding amines $6 \mathrm{~h}-\mathrm{j}$ were obtained in good yields with minor amounts of amides $\mathbf{5 h}$-j (entries 15-20). It was worth to note that substrate $\mathbf{3 g}$ bearing a $n$-butyl substituent on the amide nitrogen led to almost equal amounts of amide and amine products with catalyst $\mathbf{1}$ or $\mathbf{2}$ (entries 13,14). While catalyst $\mathbf{1}$ performed better with substrates $\mathbf{3 h}$,j bearing benzyl groups on the nitrogen (entries 15-16, 19-20), 
Table 2. Sequencial hydrosilylation of enamides $3 a-j$ into amides $5 a-j$ and amines $6 a-j$ using catalysts 1 or 2.

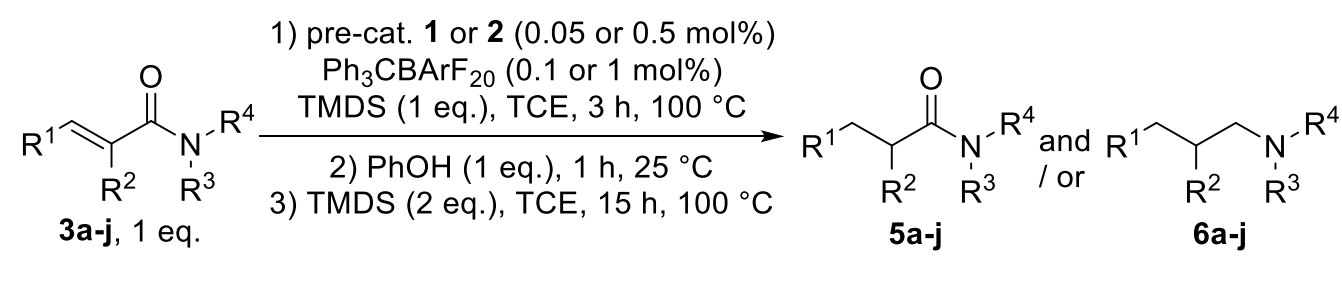

\begin{tabular}{|c|c|c|c|c|c|c|c|}
\hline Entry & $\begin{array}{c}\text { Enamide } \\
\mathbf{3}\end{array}$ & $\mathrm{R}^{1}$ & $\mathrm{R}^{2}$ & $\mathrm{R}^{3}$ & $\mathrm{R}^{4}$ & $\begin{array}{l}\text { pre-cat } \\
(\%)\end{array}$ & $\begin{array}{c}\text { Yield } \\
(\%, \text { isolated })^{[a]}\end{array}$ \\
\hline $1^{[\mathrm{c}]}$ & $3 a$ & $\mathrm{Ph}$ & $\mathrm{H}$ & $\mathrm{Bn}$ & $\mathrm{Bn}$ & $1(0.05)$ & 6a (93) \\
\hline 2 & $3 a$ & $\mathrm{Ph}$ & $\mathrm{H}$ & $\mathrm{Bn}$ & $\mathrm{Bn}$ & $2(0.05)$ & $6 a(72)$ \\
\hline 3 & $3 b$ & $\mathrm{Ph}$ & $\mathrm{H}$ & \multicolumn{2}{|c|}{$-\left(\mathrm{CH}_{2}\right)_{2}-\mathrm{O}-\left(\mathrm{CH}_{2}\right)_{2}-$} & $1(0.05)$ & $5 \mathbf{b}(36)+6 \mathbf{b}(10)$ \\
\hline 4 & $3 b$ & $\mathrm{Ph}$ & $\mathrm{H}$ & \multicolumn{2}{|c|}{$-\left(\mathrm{CH}_{2}\right)_{2}-\mathrm{O}-\left(\mathrm{CH}_{2}\right)_{2-}^{-}$} & $2(0.05)$ & $5 \mathbf{b}(16)+6 \mathbf{b}(63)$ \\
\hline 5 & $3 c$ & $\mathrm{Ph}$ & $\mathrm{H}$ & $\mathrm{Me}$ & $\mathrm{Me}$ & $1(0.05)$ & $6 c(67)$ \\
\hline 6 & $3 c$ & $\mathrm{Ph}$ & $\mathrm{H}$ & $\mathrm{Me}$ & $\mathrm{Me}$ & $2(0.05)$ & $6 c(83)$ \\
\hline 7 & $3 d$ & $\mathrm{H}$ & $\mathrm{Me}$ & $\mathrm{Bn}$ & $\mathrm{Bn}$ & $1(0.05)$ & $5 d(35)+6 d(31)$ \\
\hline 8 & $3 d$ & $\mathrm{H}$ & $\mathrm{Me}$ & $\mathrm{Bn}$ & $\mathrm{Bn}$ & $2(0.05)$ & $5 d(17)+6 d(61)$ \\
\hline 9 & $3 e$ & $\mathrm{Me}$ & $\mathrm{Me}$ & $\mathrm{Bn}$ & $\mathrm{Bn}$ & $1(0.05)$ & $5 e(27)+6 e(46)$ \\
\hline 10 & $3 e$ & $\mathrm{Me}$ & $\mathrm{Me}$ & $\mathrm{Bn}$ & $\mathrm{Bn}$ & $2(0.05)$ & $5 e(21)+6 e(51)$ \\
\hline 11 & $3 f$ & $\mathrm{Ph}$ & $\mathrm{H}$ & $\mathrm{Me}$ & $\mathrm{Ph}$ & $1(0.05)$ & $6 f(74)$ \\
\hline 12 & $3 f$ & $\mathrm{Ph}$ & $\mathrm{H}$ & $\mathrm{Me}$ & $\mathrm{Ph}$ & $2(0.05)$ & $6 f(91)$ \\
\hline 13 & $3 g$ & $\mathrm{Ph}$ & $\mathrm{H}$ & $\mathrm{H}$ & $n$-Bu & $1(0.5)$ & $5 \mathbf{g}(32)+6 \mathbf{g}(21)$ \\
\hline 14 & $3 \mathrm{~g}$ & $\mathrm{Ph}$ & $\mathrm{H}$ & $\mathrm{H}$ & $n-\mathrm{Bu}$ & $2(0.5)$ & $5 \mathbf{g}(26)+6 \mathbf{g}(34)$ \\
\hline 15 & $3 h$ & $\mathrm{Ph}$ & $\mathrm{H}$ & $\mathrm{H}$ & $\mathrm{Bn}$ & $1(0.5)$ & $5 h(11)+6 h(68)$ \\
\hline 16 & $3 h$ & $\mathrm{Ph}$ & $\mathrm{H}$ & $\mathrm{H}$ & $\mathrm{Bn}$ & $2(0.5)$ & $5 h(28)+6 h(53)$ \\
\hline 17 & $3 \mathbf{i}$ & $\mathrm{Ph}$ & $\mathrm{H}$ & $\mathrm{H}$ & $\mathrm{Ph}$ & $1(0.5)$ & $5 \mathbf{i}(8)+6 \mathbf{i}(64)$ \\
\hline 18 & $3 \mathbf{i}$ & $\mathrm{Ph}$ & $\mathrm{H}$ & $\mathrm{H}$ & $\mathrm{Ph}$ & $2(0.5)$ & $5 \mathbf{i}(9)+6 \mathbf{i}(83)$ \\
\hline 19 & $3 \mathbf{j}$ & $\mathrm{Ph}$ & $\mathrm{H}$ & $\mathrm{H}$ & $\begin{array}{l}-\mathrm{CH}_{2}-1- \\
\text { thiophene }\end{array}$ & $1(0.5)$ & $5 \mathbf{j}(5)+6 \mathbf{j}(82)$ \\
\hline 20 & $3 \mathbf{j}$ & $\mathrm{Ph}$ & $\mathrm{H}$ & $\mathrm{H}$ & $\begin{array}{l}-\mathrm{CH}_{2}-1- \\
\text { thiophene }\end{array}$ & $2(0.5)$ & $5 \mathbf{j}(21)+6 \mathbf{j}(43)$ \\
\hline
\end{tabular}

[a] isolated yield (\%) after flash chromatography or recrystallisation; $\mathrm{Ph}_{3} \mathrm{CBArF}_{20}$ : trityl tetra(pentafluorophenyl)borate;

TMDS: 1,1,3,3-tetramethyldisiloxane; TCE: 1,1',2,2'-tetrachloroethane.

catalyst 2 was more effective with conjugated amide $\mathbf{3 i}$ substituted by a phenyl (entries 17,18).

Regarding the reaction mechanism (Scheme 3), an ionic hydrosilylation ${ }^{[16]}$ pathway could be presumed. However, Djukic et al. had already shown through a combination of organometallic syntheses and DFT calculations a cohesive hydridoiridium(III) $\rightarrow$ silylium donor-acceptor complex could exist. ${ }^{[12 h, 17]}$ Hence, we assumed our reaction pathway may differentiate from the others by the activation mode of the silane. As already calculated before by us, the necessary dechlorination of precatalyst $\mathbf{1}$ or $\mathbf{2}$ to yield putative electron deficient cationic intermediate 8 results from a reaction with an in-situ-produced form of a stabilised silylium cation generated by the reaction of the tritylium cation with the silane reagent (Scheme 3 ). ${ }^{[12 h, 18]}$ For instance, the reaction of $\mathrm{Et}_{3} \mathrm{SiH}$ with $\mathrm{Ph}_{3} \mathrm{C}^{+}$is expected to produce triphenylmethane and cation $\left[\mathrm{Et}_{3} \mathrm{Si}-\mathrm{H}-\mathrm{SiEt}_{3}\right]^{+}$according to Heinekey, ${ }^{[18 \mathrm{a}]}$ and our previous DFT-D computations. ${ }^{[12 \mathrm{~h}]}$ In the framework of the mechanism depicted in Scheme 3, cationic complexes $\mathbf{8} \mathbf{a}-\mathbf{b}$ and silane reagent form adducts $\mathbf{9 a - b}$ which are sources of hydrido-iridium intermediates $\mathbf{1 0 a - b}$ and silylium cation $\mathrm{R}_{3} \mathrm{Si}^{+}{ }^{[12 \mathrm{~h}, 18-20]}$ The latter may activate the carbonyl group of amide substrate $\mathbf{3 a}$ and generate silyloxy carbonium species $\mathbf{A}$. Reaction with the first equivalent of the iridium hydride complex 10 affords silyl ketene aminal 4 resulting from a 1,4-addition addition as well as the cationic iridium complex $\mathbf{8}$. Afterwards, the addition of one equivalent of phenol allows the protodesilylation of the enolate $\mathbf{4}$ and affords amide $\mathbf{5 a}$. Reaction with the second equivalent of silylium cation and iridium hydride complex $\mathbf{1 0}$ leads first to silyloxy carbonium species $\mathbf{B}$ which is then reduced into silyl hemiacetal $\mathbf{C}$. At this stage, elimination of a silyloxide fragment may be helped by any electrophilic species present in the medium to lead to the iminium intermediate $\mathbf{D}$ which we evidenced by mass spectrometry in a previous study. ${ }^{[12 h]}$ The latter can then react with the third equivalent of the iridium hydride complex 10 and affords the amine product $\mathbf{6 a}$ along with the cationic iridium catalytic species 8 (Scheme 3). 


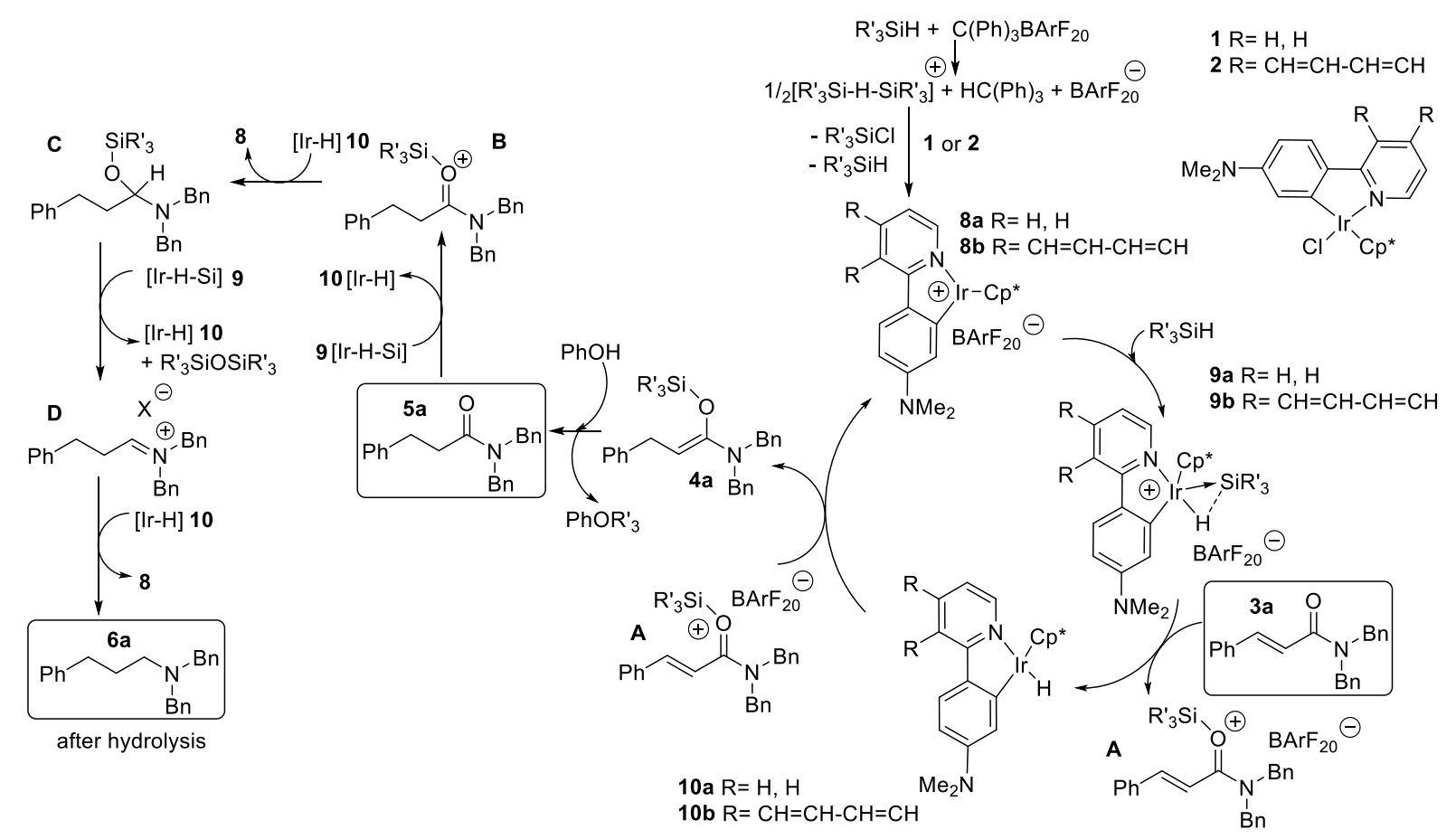

Scheme 3. Reaction mechanism of the sequential hydrosilylation of enamide $3 \mathrm{a}$ into amide $5 \mathrm{a}$ and amine 6 a catalyzed by iridium(III) complex $\mathbf{1}$ or $\mathbf{2}$ and $\mathrm{Ph}{ }_{3} \mathrm{CBArF} 20$, trityl tetra(pentafluorophenyl)borate

\section{Conclusion}

We have shown accessible cationic iridium "II metallacycles catalyze effectively the one-pot sequential double hydrosilylation of challenging $\alpha, \beta$-unsaturated secondary and tertiary amides to afford in a controlled and selective way the corresponding reduced products, that is to say the related secondary and tertiary amides and amines. The catalytic hydrosilylation reactions described herein proceeded with low catalyst loadings, in good yields and high chemoselectivities. The critical silyl ketene aminal intermediate has been observed and characterized by using control experiments, mass spectrometry and state of the art Nuclear Magnetic Resonance analyses. The present achievements indicate a promising potential of catalysts based on metallacycles for future significant developments in one-pot multicatalytic synthesis and therefore the production of highly functionalized and complex organic molecules.

\section{Experimental Section}

General procedure for the synthesis of amides ${ }^{[21]}$

In a Schlenk, a solution of trimethylphosphite $\left(\mathrm{P}(\mathrm{OMe})_{3}\right)(0.7 \mathrm{~mL}, 1.5$ eq. in dichloromethane $\left(\mathrm{CH}_{2} \mathrm{Cl}_{2}\right)(20 \mathrm{~mL})$ is cooled at $0^{\circ} \mathrm{C}$ under nitrogen gas. After addition and solvation of iodine $\left(\mathrm{I}_{2}\right)(1.52 \mathrm{~g}, 1.5 \mathrm{eq}$.), the carboxylic acid reagent (1.5 eq.) was added followed by triethylamine ( $\left.\mathrm{NEt}_{3}\right)(1.4 \mathrm{~mL}$, 2.5 eq.). After 10 minutes of stirring, the amine reagent ( 1 eq.) was added to the reaction. The resulting mixture was first stirred at $0^{\circ} \mathrm{C}$ for 10 minutes and then for 14 hours at room temperature. The reaction was then hydrolyzed using a saturated aqueous solution of sodium bicarbonate $\left(\mathrm{NaHCO}_{3}\right)$ and extracted three times with dichloromethane. The organic phase was subsequently washed with $\mathrm{HCl} 1 \mathrm{M}$, water and brine. After drying over magnesium sulfate $\left(\mathrm{MgSO}_{4}\right)$, solvents were evaporated and the residu was purified by flash chromatography over silica gel using a mixture of petroleum ether and ethyl acetate. Evaporation of solvents led to the desired amide as a solid or an oil.
General procedure for the hydrosilylation of conjugated amides 3 into amides 5

In a Schlenk tube, conjugated amide reagent $3(1.54 \mathrm{mmol}, 1$ eq. $)$ and iridium ${ }^{\text {III }}$ catalyst $1(0.05 \mathrm{~mol} \%$ / 0.0005 eq. / $0.34 \mathrm{mg}$ for a tertiary enamide or $0.1 \mathrm{~mol} \% / 0.001$ eq. / $0.68 \mathrm{mg}$ for a secondary enamide) are introduced. $\mathrm{Ph}_{3} \mathrm{CBArF}_{20}$ salt $(0.1 \mathrm{~mol} \% / 1.42 \mathrm{mg}$ or $1 \mathrm{~mol} \% / 14.2 \mathrm{mg})$ is then added in a glovebox. Under nitrogen, $1 \mathrm{~mL}$ of $\mathrm{CH}_{2} \mathrm{Cl}_{2}$ and TMDS (1 eq., 0.272 $\mathrm{mL}$ ) are transferred by syringe and the reaction mixture is heated at $25^{\circ} \mathrm{C}$ under stirring for 0.5 to $24 \mathrm{~h}$ (the Schlenk tube being closed under $\mathrm{N}_{2}$ ). Afterwards, the solvent is evaporated under vacuum (using a Schlenk line) to afford the desired amide $\mathbf{5}$ which was further purified by recrystallization or flash chromatography using mixtures of petroleum ether and ethyl acetate.

General procedure for the sequential hydrosilylation of conjugated amides 3 into amines 6 .

In a Schlenk tube, enamide reagent $3\left(1.54 \mathrm{mmol}, 1\right.$ eq.) and iridium ${ }^{\prime \prime \prime}$ catalyst 1 or $2(0.05 \mathrm{~mol} \%$ / $0.0005 \mathrm{eq}$ / / $0.34 \mathrm{mg}$ of 1 or $0.38 \mathrm{mg}$ of 2 for a tertiary enamide as well as $0.1 \mathrm{~mol} \% / 0.001 \mathrm{eq}$. / $0.68 \mathrm{mg}$ of 1 or 0.76 $\mathrm{mg}$ of 2 for a secondary enamide) are introduced. BArF salt $(0.1 \mathrm{~mol} \% /$ $1.42 \mathrm{mg}$ or $1 \mathrm{~mol} \% / 14.2 \mathrm{mg}$ ) is then added in a glovebox. Under nitrogen, $1 \mathrm{~mL}$ of TCE and TMDS (1 eq. $0.272 \mathrm{~mL}$ ) are transferred by syringe and the reaction is heated to $100^{\circ} \mathrm{C}$ under stirring for 3 hours (the Schlenk tube being closed under $\mathrm{N}_{2}$ ). After cooling to $25^{\circ} \mathrm{C}$, a solution of recrystallized phenol in TCE (1.54 mmol, 1 eq. in $1 \mathrm{~mL}$ TCE) was transferred by canula to the reaction mixture and the resulting solution was allowed to react for 1 hour. Afterwards, TMDS (2 eq., $0.545 \mathrm{~mL}$ ) was added and the reaction was heated to $100{ }^{\circ} \mathrm{C}$ for 15 hours. The solvent is then evaporated under vacuum (using a Schlenk line) and the reaction mixture is hydrolysed using dichloromethane $(3 \mathrm{~mL})$ and $\mathrm{NaOH} 1 \mathrm{M}(5 \mathrm{~mL})$. The resulting solution is stirred vigorously at $20^{\circ} \mathrm{C}$ during 1 hour. After extraction with dichloromethane and brine, the organic phase was dried with $\mathrm{MgSO}_{4}$ and evaporated to afford the desired amine 6 which was further purified by flash chromatography using mixtures of petroleum ether and ethyl acetate with $5 \% \mathrm{NEt} 3$. 


\section{Acknowledgements}

The University of Lille is acknowledged for a PhD fellowship (V. R.). The Région Hauts-de-France and the University of Lille are acknowledged for a $\mathrm{PhD}$ fellowship (Y. C.). The University of Budapest, ENSCL and E.U. are thanked for Erasmus fellowships (M.N. and D.K.). The CNRS, the Chevreul Institute (FR 2638), the Ministère de l'Enseignement Supérieur et de la Recherche, the Région Hauts-de-France and the FEDER are acknowledged for supporting and funding partially this work. Mr. Joseph Willy Danh (ENSCL) is thanked for his help with some experimental works. Dr. M. Kouach, Mrs N. Duhal, Mrs C. Lenglart and Ms A. Descat (Univ. Lille, CUMA / PSM-GRITA) are thanked for HRMS analyses. Mrs C. Delabre (UCCS) is thanked for GC and GC-MS analyses.

Keywords: sequential catalysis $\bullet$ hydrosilylation $\cdot$ conjugated amide $\bullet$ iridium $\bullet$ one-pot

\section{References}

[1] a) P. A. Clarke, S. Santos, W. H. C. Martin, Green Chem. 2007, 9, 438; b) C. Vaxelaire, P. Winter, M. Christmann, Angew. Chem. 2011, 123, 3685, Angew. Chem. Int. Ed. 2011, 50, 3605-3607; c) Y. Hayashi, Chem. Sci. 2016, 7,866 .

[2] a) J. Panteleev, L. Zhang, M. Lautens, Angew. Chem. 2011, 123, 9295, Angew. Chem. Int. Ed. 2011, 50, 9089; b) F. Nahra, Y. Mace, Y.; D. Lambin, O. Riant, Angew. Chem. 2013, 125, 3290, Angew. Chem. Int. Ed. 2013, 52, 3208; c) Z. Qureshi, J. Y. Kim, T. Bruun, H. Lam, M. Lautens, ACS Catal. 2016, 6, 4946; d) K. Yamamoto, Z. Qureshi, J. Tsoung, G. Pisella, M. Lautens, Org. Lett. 2016, 18, 4954; e) J. Liu, C. Kubis, R. Franke, R. Jackstell, M. Beller, ACS Catal. 2016, 6, 907; f) F. Lied, H. Žugelj, S. Kress, B. Štefane, F. Glorius, M. Lautens, ACS Catal. 2017, 7, 1378; g) C. Romano, C. Mazet, J. Am. Chem. Soc. 2018, 140, 4743. h) G.-M. Ho, L. Judkele, J. Bruffaerts, I. Marek, Angew. Chem. 2018, 130, 8144, Angew. Chem. Int. Ed. 2018, 57, 8012; i) C. Romano, D. Fiorito, C. Mazet, J. Am. Chem. Soc. 2019, 141, 16983; j) Q. Zhao, J. Zhang, M. Szostak, Chem. Commun. 2019, 55, 9003.

[3] F. Romiti, J. del Pozo, P. H. S. Paioti, S. A. Gonsales, X. Li, F. W. W. Hartrampf, A. H. Hoveyda, J. Am. Chem. Soc. 2019, 141, 17952 and references therein.

[4] a) C. M. Storey, A. Kalpokas, M. R. Gyton, T. Krämer, A. B. Chaplin, Chem. Sci. 2020, 11, 2051; b) S. H. Gilbert, V. Viseur, M. L. Clarke, Chem. Commun. 2019, 55, 6409; c) X. Shu, R. Jin, Z. Zhao, T. Cheng; G. Liu, Chem. Commun. 2018, 54, 13244; d) M. Kuepfert, A. E. Cohen, O. Cullen, M. Weck, Chem. Eur. J. 2018, 24, 18648; e) Y. Pan, C. Chen, X. Xu, H. Zhao, J. Han, H. Li, L. Xu, Q. Fan, J. Xiao, Green Chem. 2018, 20, 403; f) C. Yu, J. Zhang, G. Zhong, Chem. Commun. 2017, 53, 9902; g) J. Wang, L. Wu, X. Hu, R. Liu, R. Jin, G. Liu, Catal. Sci. Technol. 2017, 7, 4444; h) J. Xu, T. Cheng, K. Zhang, Z. Wang, G. Liu, Chem. Commun. 2016, 52, 6005; i) A. Aillerie, V. Rodriguez-Ruiz, R. Carlino, F. Bourdreux, R. Guillot, S. Bezzenine-Lafollée, R. Gil, D. Prim, J. Hannedouche, ChemCatChem 2016, 8, 2455; j) T. L. Lohr, T. J. Marks, Nature Chem. 2015, 7, 477; k) H. Pellissier, Tetrahedron 2013, 69, 7171; I) D.E. Fogg, E. N. dos Santos, Coord. Chem. Rev. 2004, 248, 2365.

[5] a) O. J. Pamies, E. Bäckvall, Chem. Rev. 2003, 103, 3247; b) Z. Shao, H. Zhang, Chem. Soc. Rev. 2009, 38, 2745; c) M. Rueping, R. M. Koenigs, I. Atodiresei, Chem. Eur. J. 2010, 16, 9350; d) C. Zhong, X. Shi, Eur. J. Org. Chem. 2010, 2010, 2999; e) L. M. Ambrosini, T. H. Lambert, ChemCatChem 2010, 2, 1373; f) A. Galvan, F. J. Fañanas, F. Rodríguez, Eur. J. Inorg. Chem. 2016 2016, 1306; g) S. P. Sancheti, Urvashi, M. P. Shah, N. T. Patil, ACS Catal. 2020, 10, 3462.

[6] a) Z. Cheng, J. Guo, Z. Lu, Chem. Commun. 2020, 56, 2229; b) W. Chen, H. Song, J. Li, C. Cui, Angew. Chem. 2020, 132, 2385, Angew. Chem. Int. Ed. 2020, 59, 2365; c) C. Xu, Y. Feng, F. Li, J. Han, Y.-M. He, Q.-H. Fan,
Organometallics 2019, 38, 3979; d) J. Guo, B. Cheng, X. Shen, Z. Lu, J. Am. Chem. Soc. 2017, 139, 15316; e) A. Di Giuseppe, R. De Luca, R. Castarlenas J. J. Pérez-Torrente, M. Crucianelli, L. A. Oro, Chem. Commun. 2016, 52, 5554 f) X.-M. Zeng, Chem. Rev. 2013, 113, 6864

[7] a) Y. Sasson, J. Blum, J. Org. Chem. 1975, 40, 1887; b) X. Wang, Z. Han, Z. Wang, K. Ding, Angew. Chem.Int. Ed. 2012, 51, 936; Angew. Chem. 2012 124, 960; c) B. Ding, Z. Zhang, Y. Liu, M. Sugiya, T. Imamoto, W. Zhang, Org. Lett. 2013, 15, 3690; d) W. Li, X.-F. Wu, Eur. J. Org. Chem. 2015, 331; e) S. Guo, P. Yang, J. Zhou, Chem. Commun. 2015, 51, 12115; f) M. Shevlin, M. R. Friedfeld, H. Sheng, N. A. Pierson, J. M. Hoyt, L.-C. Campeau, P. J. Chirik, J. Am. Chem. Soc. 2016, 138, 3562; g) P. Puylaert, R. van Heck, Y. Fan, A. Spannenberg, W. Baumann, M. Beller, J. Medlock, W. Bonrath, L. Lefort, S Hinze, J. G. de Vries, Chem. Eur. J. 2017, 23, 8473; h) R. Farrar-Tobar, Z. Wei, H. Jiao, S. Hinze, J. G. de Vries, Chem. Eur. J. 2018, 24, 2725; i) B. M. Zimmermann, S. C. K. Kobosil, J. F. Teichert, Chem. Commun., 2019, 55, 2293. [8] a) E. Keinan, D. Perez, J. Org. Chem. 1987, 52, 2576; b) K. Takeshita, Y. Seki, K. Kawamoto, S. Murai, N. Sonoda, J. Org. Chem. 1987, 52, 4864; c) C. Deutsch, N. Krause, B. H. Lipshutz, Chem. Rev. 2008, 108, 2916; d) E. Blondiaux, T. Cantat, Chem. Commun. 2014, 50, 9349; e) A. Volkov, F. Tinnis, T. Slagbrand, I. Pershagen, H. Adolfsson, Chem. Commun. 2014, 50, 14508; f) H. Qrareya, D. Dondi, D. Ravelli, M. Fagnoni, ChemCatChem 2015 7, 3350; g) T. J. Steiman, C. Uyeda, J. Am. Chem. Soc. 2015, 137, 6104; h) N Komine, M. Abe, R. Suda, M. Hirano, Organometallics 2015, 34, 432; i) N. L. Lampland, A. Pindwal, S. R. Neal, S. Schlauderaff, A. Ellern, A. D. Sadow, Chem. Sci. 2015, 6, 6901; j) R. Zhou, Y. Y. Goh, H. Liu, H. Tao, L. Li, J. Wu Angew. Chem. 2017, 129, 16848, Angew. Chem. Int. Ed. 2017, 56, 16621.

[9] a) D. Vargová, I. Némethová, K. Plevová, R. Šebesta, ACS Catal. 2019 , 9, 3104; b) C. C. Chong, B. Rao, R. Kinjo, ACS Catalysis 2017, 7, 5814; c) U. Kazmaier, Org. Chem. Front. 2016, 3, 1541; d) J. P. Phelan, J. A. Ellman Beilstein J. Org. Chem. 2016, 12, 1203.

[10] a) Y. Kim, S. Chang, Angew. Chem. 2016, 128, 226, Angew. Chem. Int. Ed. 2016, 55, 218; b) A. Chardon, T. Mohy El Dine, R. Legay, M. De Paolis, J. Rouden, J. Blanchet, Chem. Eur. J. 2017, 23, 2005; c) D. Vargová, J. M. Pérez, S. R. Harutyunyan, R. Šebesta, Chem. Commun. 2019, 55, 11766.

[11] a) N. Kumagai, M. Shibasaki, Chem. Eur. J. 2016, 22, 15192; b) Y. Yamashita, R. Igarashi, H. Suzuki, S. Kobayashi, Org. Biomol. Chem. 2018, 16, 5969; c) H. Suzuki, I. Sato, Y. Yamashita, S. Kobayashi, J. Am. Chem. Soc. 2015, 137, 4336; d) B. Sun, P. V. Balaji, N. Kumagai, M. Shibasaki, J. Am. Chem. Soc. 2017, 139, 8295; e) K. Tokumasu, R. Yazaki, T. Ohshima, J. Am. Chem. Soc. 2016, 138, 2664.

[12] a) W. Iali, F. La Paglia, X.-F. Le Goff, D. Sredojevic, M. Pfeffer, J.-P. Djukic, Chem. Commun. 2012, 48, 10310; b) Y. Corre, W. Iali, M. Hamdaoui, X. Trivelli, J.-P. Djukic, F. Agbossou-Niedercorn, C. Michon, Catal. Sci. Technol. 2015, 5, 1452; c) C. Michon, K. Maclntyre, Y. Corre, F. Agbossou-Niedercorn, ChemCatChem 2016, 8, 1755; d) Y. Corre, C. Werlé, L. Brelot-Karmazin, J.-P Djukic, F. Agbossou-Niedercorn, C. Michon, J. Mol. Catal. A: Chem. 2016, 423, 256; e) Y. Corre, V. Rysak, F. Capet, J.-P. Djukic, F. Agbossou-Niedercorn, C. Michon, Chem. Eur. J. 2016, 22, 14036; f) Y. Corre, V. Rysak, X. Trivelli, F. Agbossou-Niedercorn, C. Michon, Eur. J. Org. Chem. 2017, 2017, 4820; g) V. Rysak, Y. Corre, F. Agbossou-Niedercorn, C. Michon, Chimica OGGI Chemistry Today 2017, 35, 27; h) Y. Corre, X. Trivelli, F. Capet, J.-P. Djukic, F. Agbossou-Niedercorn and C. Michon, ChemCatChem 2017, 9, 2009; i) V. Rysak, A. Descamps-Mandine, P. Simon, F. Blanchard, L. Burylo, M..Trentesaux, M. Vandewalle, V. Collière, F. Agbossou-Niedercorn, C. Michon, Catal. Sci. Technol. 2018, 8, 3504.

[13] a) Y. Motoyama, M. Aoki, N. Takaoka, R. Aoto, H. Nagashima, Chem Commun. 2009, 1574; b) O. O. Kovalenko, A. Volkov, H. Adolfsson, Org. Lett. 2015, 17, 446; c) S. Das, Y. Li, L.-Q. Lu, K. Junge, M. Beller, Chem. Eur. J. 2016, 22, 7050; d) B. Li, J.-B. Sortais, C. Darcel, RSC Adv. 2016, 6, 57603.

[14] D. A. Oare, M. A. Henderson, M. A. Sanner, C. H. Heathcock, J. Org. Chem. 1990, 55, 132.

[15] a) J. K. Paulasaari, W. P.Weber, Macromol. Chem. Phys. 2000, 201 1585; b) Uhlig, F. D., \& Marsmann, H. C. (2003). Silicon-29 NMR some practical Aspects. In Gelest Catalogue (Silicon Compounds: Silanes \& Silicones ed., pp. 195-195). Morrisville, PA. USA: Eigenverlag.

[16] a) M. Iglesias, F. J. Fernández-Alvarez, L. A. Oro, Coord. Chem. Rev. 2019, 386, 240; b) M. C. Lipke, A. L. Liberman-Martin, T. Don Tilley, Angew. Chem. 2017, 129, 2298, Angew. Chem. Int. Ed. 2017, 56, 2260; c) J. Fuchs, H. F. T. Klare, M. Oestreich, ACS Catal. 2017, 7, 8338; d) M. Oestreich, 
Angew. Chem. 2016, 128, 504, Angew. Chem. Int. Ed. 2016, 55, 494; e) M. Oestreich, J. Hermeke, J. Mohr, Chem. Soc. Rev. 2015, 44, 2202; f) M. Iglesias, F. J. Fernández-Alvarez, L. A. Oro, ChemCatChem 2014, 6, 2486; g) T. T. Metsänen, P. Hrobárik, H. F. T. Klare, M. Kaupp, M. Oestreich, J. Am. Chem. Soc. 2014, 136, 6912; h) W. Wang, P. Gu, Y. Wang, H. Wei, Organometallics 2014, 33, 847; i) M. Iglesias, P. J. Sanz-Miguel, V. Polo, F. J. Fernández-Alvarez, J. J. Pérez-Torrente, L. A. Oro, Chem. Eur. J. 2013, 19, 17559; j) O. G. Shirobokov, L. Kuzmina, G. I. Nikonov, J. Am. Chem. Soc. 2011, 133, 6487; k) J. Yang, P. S. White, M. Brookhart, J. Am. Chem. Soc. 2008, 130, 17509; I) R. M. Bullock, Chem. Eur. J. 2004, 10, 2366.

[17] a) M. Hamdaoui, M. Ney, V. Sarda, L. Karmazin, C. Bailly, N. Sieffert, S. Dohm, A. Hansen, S. Grimme. J.-P. Djukic, Organometallics 2016, 35, 2207; b) D. H. Binh, M. Hamdaoui, D. Fischer-Krauser, L. Karmazin, C. Bailly, J.-P. Djukic, Chem. Eur. J. 2018, 24, 17577.

[18] a) S. J. Connelly, W. Kaminsky, D. M. Heinekey, Organometallics 2013, 32, 7478; b) M. Nava, C. A. Reed, Organometallics 2011, 30, 4798; c) S. P. Hoffmann, T. Kato, F. S. Tham, C. A. Reed, Chem. Commun. 2006, 767.

[19] a) M. F. Ibad, P. Langer, A. Schulz, A. Villinger, J. Am. Chem. Soc. 2011, 133, 21016; b) C. A. Reed, Acc. Chem. Res. 1998, 31, 325.

[20] a) C. Scheeren, F. Maasarani, A. Hijazi, J.-P. Djukic, M. Pfeffer, S. D. Zaric, X.-F. LeGoff, L. Ricard, Organometallics 2007, 26, 3336; b) Y. Hu, L. Li, A. P. Shaw, J. R. Norton, W. Sattler, Y. Rong, Organometallics 2012, 31, 5058. [21] a) Q. L. Luo, L. Lv, Y. Li, J. P. Tan, W. Nan, Q. Hui, Eur. J. Org. Chem. 2011, 6916; b) N. Zhang, B. Li, H. Zhong, J. Huang, Org. Biomol. Chem. 2012, 10,9429 . 
